\title{
ORIGINAL CONTRIBUTION \\ Implementation of Lean Methodology on the Main Assembly Line of an Automotive Plant to Enhance Productivity
}

\author{
Amber Iqbal ${ }^{1}$, M. Nasir Bashir ${ }^{2 *}$, Asna Alam ${ }^{3}$, M. Bilal Asif ${ }^{4}$, Iqra Arshad ${ }^{5}$ \\ PNEC, National University of Sciences and Technology, Karachi, Pakistan
}

\begin{abstract}
Productivity can be enhanced by reducing wastages in a process while maintaining or increasing the amount of output. This is real work carried out in the automotive industry. In our work, we enhanced the productivity of the assembly line in an automotive plant by applying lean methodologies. There is an extensive range of tools available to remove all kinds of wastes, from which we selected the following two tools to remove waste that will enhance productivity, Value Stream Map (VSM) and Overall Equipment Effectiveness (OEE). The purpose of using VSM is that it easily highlights the bottlenecks in any existing process. For VSM we need to conduct a time and motion study to understand the structure of an organization. At the same time, OEE helps us measure the efficiency of our system being utilized. After applying these tools, we easily identified the parts which needed improvement in the process. It has reduced our cycle time of sub-assemblies by $50 \%$ and transportation time by $60 \%$. This overall enhanced the productivity of the system by $20 \%$. The index of OEE increased by $2 \%$. Our work has improved the productivity of the assembly line in an automotive plant. In the future this work can be further improved by our successors for better productivity, fulfilling future customer needs.
\end{abstract}

Index Terms - Lean Methodology, Value Streaming Map, 5S, Cycle Time, Standard Work, Productivity Enhancement

Received: 2 January 2020; Accepted: 13 April 2020; Published: 19 June 2020

(C) 2020 JITDETS. All rights reserved.

\section{INTRODUCTION}

In today's competitive cooperate world, industries are required to produce products in small lead times, low costs, and provide high customer service levels for better business survival. Due to this reason companies have become more focused on customer service by reducing their lead times. The concept of lean was introduced by Toyota which changed the face of production by helping businesses quickly identify and resolve any issue that could lead to faulty production. This concept is used to maximize customer value and minimize wastes to increase the value of the product [1].

The plant understudy has the capacity to produce 550 bikes/shift. Our objective is to enhance productivity in order to cater to the higher demands of the customer and to reduce the overall cycle time of each part. Assembly line design and balancing are some of the challenging aspects of automotive production lines [2]. The focus of our work is to identify and eliminate bottlenecks in the process. Hence, the lean methodology is applied to remove these bottlenecks. We basically emphasize on eliminating wastages, reducing inventories and improve cycle time. Productivity was enhanced by using these two tools: VSM and OEE [3].

Firstly, VSM will create a clear flow of production which will help us easily identify the bottlenecks in our assembly line. Then, OEE will determine the degree of efficiency we lack, from our standards [4]. In this paper, we improved the productivity of automotive plants using these tools.
Further, this paper covers future possibilities for our successors to further improve our applied work.

\section{LITERATURE REVIEW}

In the early days of manufacturing, corporations did not focus on being efficient [5], which is why there was a surplus of labor against enough service. And over the years Toyota Motor Company (TMC) developed a completely new system of production, which eventually enhanced the production by eliminating wastes. This new system had the ability to easily respond to the market's increasing need and with further modification, we today know this methodology as Lean Manufacturing [6, 7].

This methodology makes every process efficient by reducing wastes, which in our case are the bottlenecks and overall cycle time on the assembly line. According to the concept of lean suggested by Toyota, wastages can be of various kinds i.e. overproduction, transportation, inventory, waiting, delay, motion and defects. Wastages in our case can be inappropriate utilization of workers on the line, production space and machine placement.

VSM is a technique used to analyze the complete flow of activities and information. It helps the operation managers and engineers the complete process i.e. since the order is received till it is delivered to the customer. The cycle time of every process is recorded for a clear picture. So, facilitates the identification of the Value Added and Non-Value Added

\footnotetext{
${ }^{*}$ Corresponding author: M. Nasir Bashir

†Email: nasir@pnec.nust.edu.pk
} 
services in our process [8].

OEE is a key performance indicator. It is the measure of to what extent we are the right job. It indicates to us whether we are meeting the required criteria or not. Its calculation is based on a composite of six big wastes of equipment $[4,9]$.

\section{A. Time and Motion Study}

Time study is a method to set a standard time required for a specific task. Productivity can be improved with effective time management. It is the fundamental step required to identify the opportunities and operations that established production standards [8].

Outcomes from this method of study are below:

- Better ways of performing tasks.

- Consumption of minimum resources.

- Optimization of processes.

This is a very old technique required to enhance productivity by visualizing Value Added and Non-Value Added activities. For industries having manual operations: the time standard is determined based on effective work methods. Improved established time standards make it possible to produce more within a given time frame, increasing the efficiency of the equipment and labor involved.

The main purpose of the time and motion study is to improve the productivity rate, increase job efficiency, and improve quality. While doing analysis for our work apart of time and motion study we also incorporated unexpected delays. After all the work we were able to draw a Current State Value Stream Map (CSVSM).

\section{B. VSM}

The VSM is used to identify problems in a flow of process [3]. It does not resolve the problem rather it is highlighted. Current state VSM showing the assembly line and highlighting the problematic areas is shown below in Fig. 1

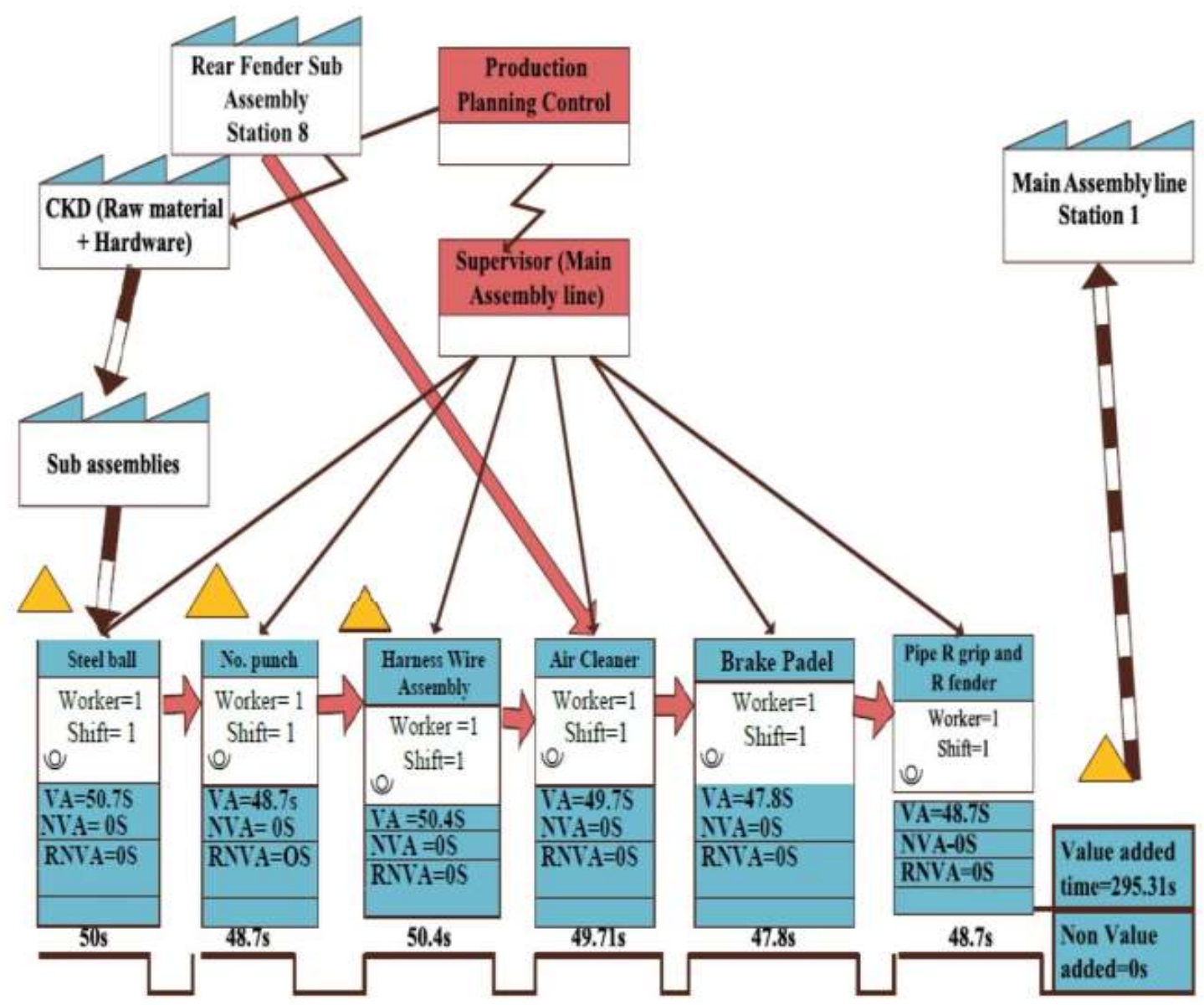

Fig. 1. Illustration of VSM

There are several symbols that are used for displaying information on VSM. Some of the frequently used symbols are illustrated in Fig. 2, as given below. 


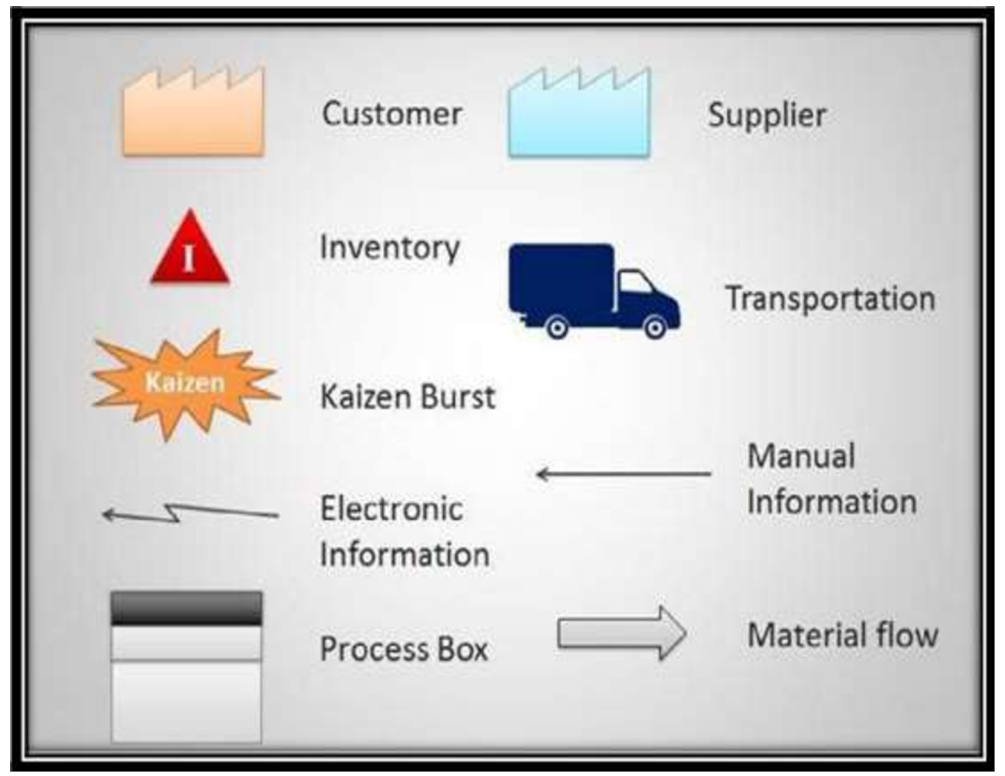

Fig. 2. Legends of VSM

Now after we have created a CS-VSM, required improvements are highlighted using Kaizen Burst. These improvements are basically our

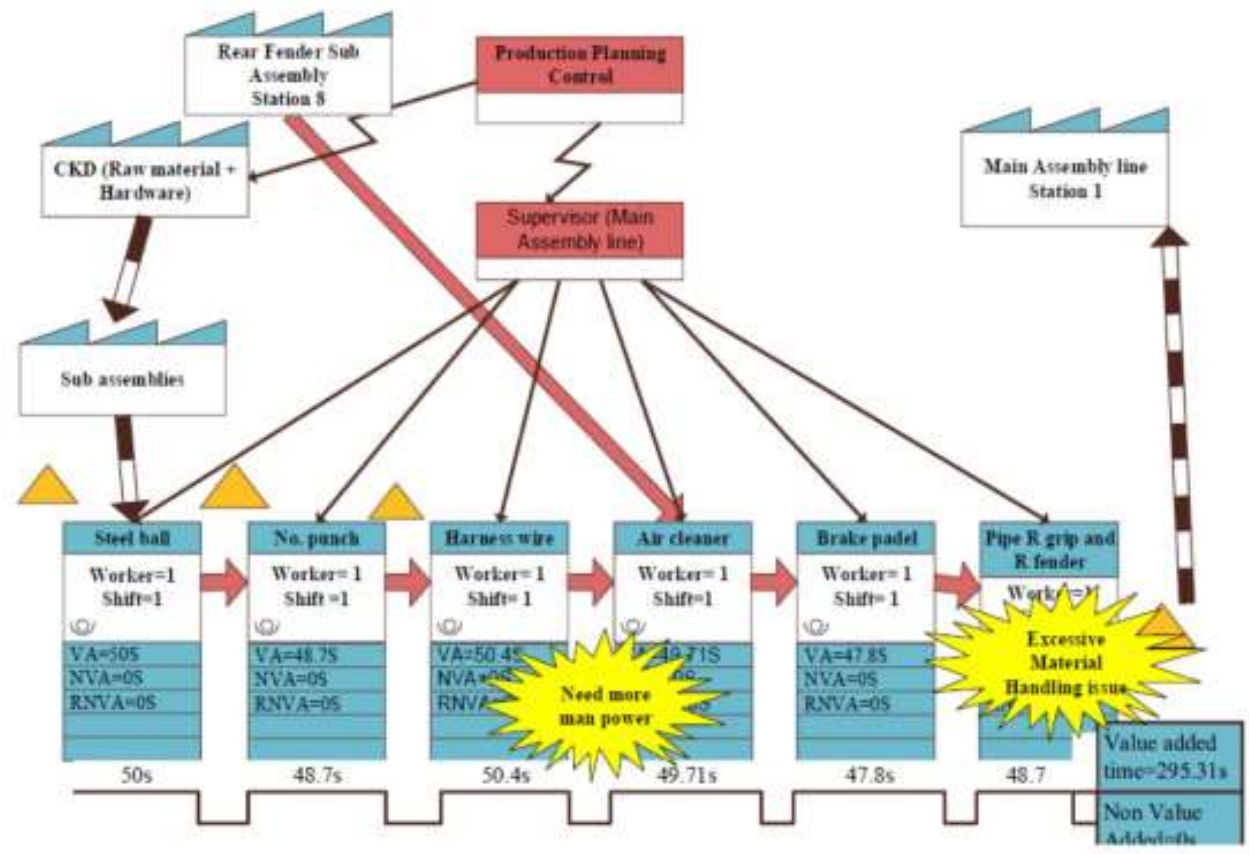

Fig. 3. Current state VSM with highlighted wastages

Moving forward, after identifying the areas of improvement, we have listed them below. After removing these wastages we'll be able to enhance productivity.

- Improper material handling.

- Long transportation route.

- Improper distribution of tasks.

Up till now, we have created CS-VSM, then identified problematic areas and then after that, we will create a Future State VSM. FSVSM will be VSM showing the increase in efficiency after we have removed the bot- tlenecks and reduced the cycle time of the overall process, virtually. This motivates the organizations to implement the suggested improvements.

\section{OEE}

OEE provides a systematic process to easily identify sources of wastages so you can apply one's resources to improve your performance. One can also say that it is a comprehensive measurement of how well equipment is performing against its given design capacity $[4,10]$. the main goal behind OEE is to minimize and eliminate the inefficiency causes 
in the manufacturing process $[11,12]$. The most common inefficiency causes in the industry are called "Six Big Losses". Following are stated below:

- Downtime Losses

- Setup and adjustments

- Small stops

- Startup rejects

- Production rejects

- Reduced speed

When OEE is applied to an assembly line it is known as Overall Line Efficiency, used to measure assembly-line efficiency. It indicates how well an assembly line is running compared to how well in=t should be running. This is the effectiveness of the assembly line, the most important factor when enhancing productivity.

OEE provides us with quantitative analysis which can be compared to the standard values of the industry. Following are the three parameters based on which we calculate the Overall Line Efficiency.

1) Availability: It is a ratio of operating time to the planned production time. Planned downtime and breakdown losses come under availability losses. The formula is stated below:

$$
\text { Availibility }=\frac{\text { Operating Time }}{\text { Planned Production Time }}
$$

2) Performance: Performance of an assembly line is the ratio of the product of ideal cycle time and total pieces produced at that time to the operating time. Minor stoppages and speed losses during production come under performance losses. The formula stated below:

$$
\text { Performance }=\frac{\text { Ideal Cycle Time } \times \text { Total pieces }}{\text { Operating Time }}
$$

3) Quality: It is the ratio between conforming pieces to total pieces produced. The quality loss occurs due to rejection during production or on startup the shift. The formula to calculate losses due to quality is stated below:

$$
\text { Quality }=\frac{\text { Good pieces }}{\text { Total pieces }}
$$

4) Overall line efficiency: The overall line efficiency is the product of quality, availability, and performance, as given below.

Overall Line Efficiency $=$ Availibilty $\times$ Quality $\times$ Performance

\section{Methodology}

To calculate Overall Line Efficiency, we need historic data. We collected the data for the past three months which is in Table I.

TABLE I

OVERALL LINE EFFICIENCY CALCULATIONS

\begin{tabular}{llllll}
\hline \hline Month & Days & Total Piece & Defective Piece & Quality Defect & Good Pieces \\
\hline 1. October & 26 & 11,939 & 756 & 86 & 11,097 \\
2. November & 26 & 12,800 & 1007 & 91 & 11,702 \\
3. December & 26 & 13,075 & 980 & 79 & 12,016 \\
Total & 78 & 37,814 & 2,743 & 256 & 34,815 \\
\hline \hline
\end{tabular}

1) Breakdown time: The time duration for which the assembly line remains out of work is to break down time. We add individual months to break down time and take its average as shown in Table II.

TABLE II

BREAKDOWN TIME

\begin{tabular}{lll}
\hline \hline Month & Time in Hrs. & Time in Min. \\
\hline 1. Oct & 17 & 1,020 \\
2. Nov & 14 & 840 \\
3. Dec & 21 & 1,260 \\
Total & 52 hrs. & $3,120 \mathrm{sec}$ \\
\hline \hline
\end{tabular}

2) Allowances: It is the free time needed and allotted so that the workers to take a break from work. This increases their efficiency because the job is repetitive in nature (Allowances). Following are the various allowance provided to the workers in a single working day as shown in Table III.

TABLE III

ALLOWANCE CALCULATED

\begin{tabular}{ll}
\hline \hline Activity Name & Time in Min. \\
\hline 1. Tea break & 20 \\
2. Lunch & 45 \\
3. Prayer & 15 \\
4. Opening and closing meeting & 10 \\
Total & 90 min. \\
\hline \hline
\end{tabular}

3) The calculation for availability: The calculations for vailability are as follows:

Availibility $=$ Operating Time $/$ Planned Production Time
Available production hours $=9.5 \mathrm{hrs} .=570 \mathrm{~min}$.

Production min. $/$ day $=$ Available production hours - Allowances/day

$=570-90=480 \mathrm{~min}$.

Planned Production min. $/$ month $=480$ min. $* 26$ days $=12,480 \mathrm{~min}$.

Operating time $/$ month $=$ Total production min. $-($ Breakdown time due to quality or other issues)

Operation time calculation is mentioned in Table IV.

TABLE IV

OPERATION TIME CALCULATED

\begin{tabular}{ll}
\hline \hline Total Production (Min) - Breakdown Time & Operating Time in Min. \\
\hline $1.12,480-1020$ & 11,460 \\
$2.12,480-840$ & 11,640 \\
$3.12,480-1,260$ & 11,220 \\
Total & $34,320 \mathrm{~min}$. \\
\hline \hline
\end{tabular}

So, the availability per month is mentioned in Table V.

TABLE V

AVAILABILITY CALCULATED

\begin{tabular}{ll}
\hline \hline Operating Time/Planned Production Time & Availability (Min) \\
\hline $1.11,460 / 12,480$ & 0.918 \\
2. $11,640 / 12,480$ & 0.933 \\
3. $11,220 / 12,480$ & 0.899 \\
Average & $0.915 \mathrm{~min}$. \\
\hline \hline
\end{tabular}




\section{4) The calculation for quality:}

Quality=(Good pieces)/(Total peices)

TABLE VI

QUALITY OF PIECES PRODUCED

\begin{tabular}{ll}
\hline \hline S.no. Good Pieces/Total Pieces & Quality (Parts) \\
\hline $1.11,097 / 11,939$ & 0.929 \\
$2.11,702 / 12,800$ & 0.906 \\
$3.12,016 / 13,075$ & 0.919 \\
Average & 0.918 \\
\hline \hline
\end{tabular}

5) The calculation for performance: Performance is calculated as follows: Performance $=\left(\right.$ Ideal Cycle Time ${ }^{*}$ Total pieces $) /($ Operating Time $)$ The cycle time at which the assembly line is operating is 52 seconds. We have calculated the operating time now, so we calculate the performance as shown in Table VII below.

TABLE VII

PERFORMANCE CALCULATED

\begin{tabular}{ll}
\hline \hline S.No. Cycle Time $\times$ Total Pieces/Operating Time & Performance \\
\hline 1. $0.866 * 11,939 / 11,460$ & 0.902 \\
2. $0.866 * 12,800 / 11,640$ & 0.952 \\
3. $0.866 * 13,075 / 11,520$ & 0.957 \\
Average & 0.94 \\
\hline \hline
\end{tabular}

So, overall line efficiency is:

Overall Line Efficiency $=$ Availibilty*Quality*Performance

$=0.915 * 0.918 * 0.94=78 \%$

6) Comparison with standard value: These are the standard values for overall line efficiency. Although it varies from industry to industry but in case of automobile following standards mentioned in Table VIII is used to measure the effectiveness of the assembly line.

TABLE VIII

COMPARISON WITH A STANDARD VALUE

\begin{tabular}{lll}
\hline \hline S. No. OLE Factor & Standard Values & OLE Values (Actual) \\
\hline 1. Availability & $90 \%$ & $91.5 \%$ \\
2. Quality & $95 \%$ & $91.8 \%$ \\
3. Performance & $99 \%$ & $94 \%$ \\
OLE & $85 \%$ & $78.9 \%$ \\
\hline \hline
\end{tabular}

\section{Results}

We have used both qualitative and quantitative data for the analysis. The flow of production is disrupted due to excessive material handling and worker fatigue which must be removed in order to increase productivity by adding a simple roller conveyor as per requirements. Similarly, Sub-assemblies are far away from the main assembly line which needs to bring closer to the main assembly line by creating a mezzanine floor. This really helps us to reduce transportation time which is non-value added and hitting directly to our target standard time. In addition to this, material handling is improved by modifying trollies to adjust maximum no. Of parts to reduce transportation which ultimately reduces defects.

We can improve our processes by adding auto loaders to the machines to reduce worker fatigue and to enhance productivity. In addition to this, proper jigs and fixtures designed for the ease of workers, so they can work with maximum efficiency.

Productivity improvement is to do the right things better and make it a part of the continuous improvement process. Therefore, we adopted an efficient productivity improvement technique to enhance productivity.

\section{A. Methods of Improving Productivity}

- Increase output while input remains the same

- Decrease input while output remains the same

- Increase input resulting in a very large increase in output

- Decrease input by a very large amount with a resultant small reduction in output

Its formula is Productivity = Output $/$ Input

We first focused on our sub-assemblies in which we reduced our work content to eliminate non-value-added time. In this way, we can enhance our productivity. We calculated productivity by using the total number of workers on the shop floor as an input while the daily production of 550 motorcycle /shift as an output. The productivity is calculated and mentioned in the Table IX below.

TABLE IX

COMPARISON BETWEEN PRODUCTIVITY

\begin{tabular}{lc}
\hline \hline Before & After \\
\hline \multicolumn{2}{c}{ Productivity } \\
\hline 7.33 production/ worker & $=550 / 73$ \\
Increase in productivity by & 0.2 Production $/$ worker \\
\hline \hline
\end{tabular}

Now, we added those two spare workers to main assembly line and distribute the task equally among each station, then the average time of each station will be reduced and became:

Average Time of each station $=\sum$ Total task time of 26 stations $/ 28$ station $=1311 / 28=46.88=47 \mathrm{sec} /$ station

Expected output $=$ Available time $/$ Cycle time $=8 * 60 * 60 / 47 \mathrm{sec}=612.76=613$ Motorcycle per day

Now, we collected the samples, after implementation of improvements.

TABLE X

DATA COLLECTED AFTER IMPROVEMENTS

\begin{tabular}{llllll}
\hline \hline Month & Days & Total Piece & $\begin{array}{l}\text { Defective } \\
\text { Piece }\end{array}$ & $\begin{array}{l}\text { Quality } \\
\text { Defect }\end{array}$ & $\begin{array}{l}\text { Good } \\
\text { Pieces }\end{array}$ \\
\hline 1. March & 26 & 13200 & 726 & 56 & 12474 \\
2. April & 26 & 13800 & 865 & 64 & 12935 \\
3. May & 26 & 14600 & 670 & 63 & 13930 \\
Total & 78 & 41600 & 2261 & 183 & 39339 \\
\hline \hline
\end{tabular}

Breakdown time is recorded as:

TABLE XI

BREAKDOWN TIME

\begin{tabular}{lll}
\hline \hline Month & Time in Hrs & Time in Min \\
\hline 1 Oct & 8 & 480 \\
2 Nov & 17 & 1020 \\
3 Dec & 13 & 780 \\
Total & 38 & 2280 \\
\hline \hline
\end{tabular}

Total operating time is:

TABLE XII

OPERATING TIME

\begin{tabular}{ll}
\hline \hline Total Production (Min) - Breakdown Time & Operating Time (min) \\
\hline $112480-1200$ & 12000 \\
$212480-960$ & 11460 \\
$312480-1140$ & 11700 \\
Total & 35160 \\
\hline
\end{tabular}


Availability is calculated as:

TABLE XIII

AVAILABILITY CALCULATED

\begin{tabular}{ll}
\hline \hline Operating Time/ Planned Production Time & Availibility (Min) \\
\hline $111760 / 12480$ & 0.962 \\
$211460 / 12480$ & 0.918 \\
$311700 / 12480$ & 0.938 \\
Average & 0.939 \\
\hline \hline
\end{tabular}

Quality Calculation:

TABLE XIV

QUALITY CALCULATED

\begin{tabular}{lll}
\hline \hline Good Pieces & Total Pieces & Quality (Parts) = Good Pieces / Total Pieces \\
\hline 112474 & 13200 & 0.945 \\
212935 & 13800 & 0.937 \\
313930 & 14600 & 0.954 \\
39339 & 41600 & 0.918 \\
\hline \hline
\end{tabular}

Performance calculation is:
TABLE XV

PERFORMANCE CALCULATED

\begin{tabular}{ll}
\hline \hline Cycle Time $\times$ Total Pieces / Operating Time & Performance \\
\hline $10.783 * 13200 / 12000$ & 0.861 \\
$20.783 * 13800 / 11460$ & 0.943 \\
$30.783 * 14600 / 11700$ & 0.977 \\
Average & 0.927 \\
\hline
\end{tabular}

$\mathrm{OEE}=0.939 \times 0.918 \times 0.927=80 \%$

\section{B. Future State Value Stream Map}

After giving the proposal of all the highlighted area that needs to be improved, we can map Future State Value Stream Mapping (FVSM). FVSM is a significant tool of lean manufacturing, through which we can see an improved state of processes. To improve, we must keep on changing the future state into the current state for getting better results for the next trial, and hence the cycle repeats continuously. The depiction is mentioned in Fig. 4.

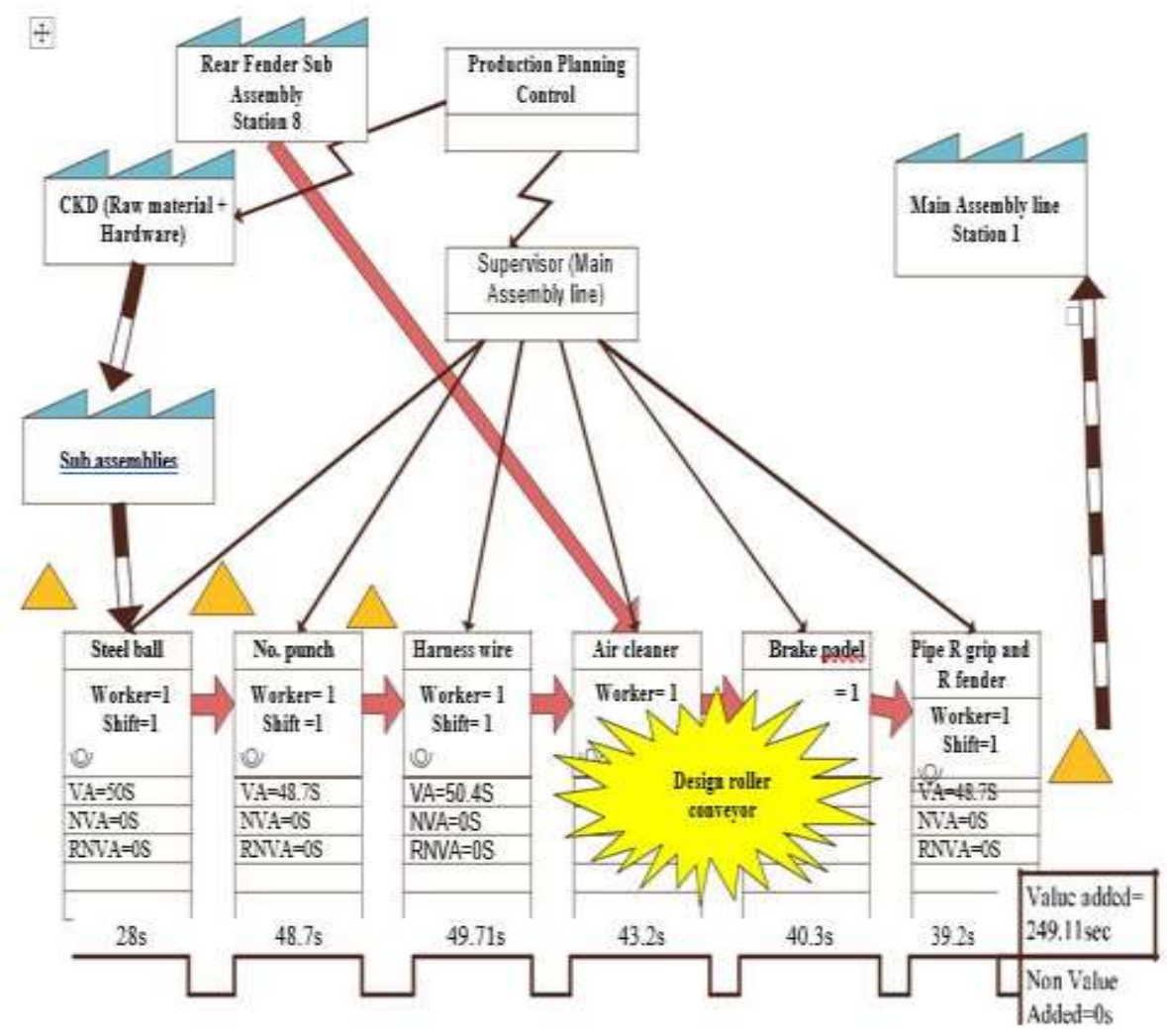

Fig. 4. Future state VSM with highlighted wastes

\section{DISCUSSION}

From Table IX, it is found that there is a $20 \%$ increase in productivity through lean implementation and a $1.1 \%$ increase in overall OEE. The overall system has been improved considerably. The defect ratio is $28 \%$ reduced due to closer sub-assemblies and improvement in material replen- ishment processes. The cycle time is reduced from $52 \mathrm{sec}$ to $47 \mathrm{sec}$ and the line is now balanced on $47 \mathrm{Sec}$ which enhances our productivity to $20 \%$. The Project plays a vital role in catering to fluctuated demands from the customer's side. 


\section{CONCLUSION AND IMPLICATIONS}

The implementation of Lean methodologies and tools to increase the operational efficiency of the production processes of the main assembly line and related sub-assemblies translated into positive results and fostered continuous improvement in the medium term. The actions presented were aimed at improving overall performance through the tools: Standard Work, current state value stream Mapping, and overall equipment efficiency. The other action improvements were identified during the process analysis. The implementation of the Value stream mapping contributes to organize and streamline. The flow of production and making it easy for us to locate and use material and equipment. This helps in the redefinition of layout and allowed a more controlled and efficient process leading to a significant reduction of time and number of transports, increasing the yield index of the assembly process. Other actions such as reducing transportation time by placing conveyors and making mezzanine floors at subassembly's process contributed significantly to the reduction of defects and the increase of the quality İndex. These actions, in addition to improving the quality of products, also improve safety. Overall equipment efficiency is checking the productivity index and Show the areas of improvement. It brings our system near to the World standard values and undoubtedly this process gives the company greater prominence in the market so that being optimized would bring great benefits to the same.

\section{LIMITATIONS AND DIRECTIONS FOR FUTURE RESEARCH}

Although our process is cost-effective to produce all kinds of products, this comes with a limitation. Our lean methodology can only be applied to plant which produce a product using manual operations. As in an automated plant, there is not much deviation in cycle times of operations. Further, their breakdown times and grade of efficiency is relatively good when compared. Hence, our methodology is only effective for manually operated plants.

\section{Declaration of Competing Interest}

The authors wish to confirm that there are no known conflicts of interest associated with this publication

\section{References}

[1] S. Nallusamy and A. Ahamed, "Implementation of lean tools in an automotive industry for productivity enhancement: A case study," International Journal of Engineering Research in Africa, vol. 29, pp. 175185, 2017. doi: https://doi.org/10.4028/www.scientific.net/JERA. 29.175

[2] A. Qattawi and S. Chalil Madathil, "Assembly line design using a hybrid approach of lean manufacturing and balancing models," Produc- tion \& Manufacturing Research, vol. 7, no. 1, pp. 125-142, 2019. doi: https://doi.org/10.1080/21693277.2019.1604274

[3] D. Correia, F. Silva, R. Gouveia, T. Pereira, and L. P. Ferreira, "Improving manual assembly lines devoted to complex electronic devices by applying lean tools," Procedia Manufacturing, vol. 17, pp. 663-671, 2018. doi: https://doi.org/10.1016/j.promfg.2018.10.115

[4] M. Singh and M. Narwal, "Measurement of Overall Equipment Effectiveness (OEE) of a manufacturing industry: An effective lean tool," International Journal of Recent Trends in Engineering and Research, vol. 3, no. 5, pp. 268-275, 2017.

[5] C. M. Tung, "Vertical integration for smart manufacturing-The dynamic capability perspective," Journal of Advances in Technology and Engineering Research, vol. 4, no. 2, pp. 30-38, 2018. doi: https://doi. org/10.20474/jater-4.2.3

[6] L. Botti, C. Mora, and A. Regattieri, "Integrating ergonomics and lean manufacturing principles in a hybrid assembly line," Computers \& Industrial Engineering, vol. 111, pp. 481-491, 2017. doi: https://doi. org/10.1016/j.cie.2017.05.011

[7] C. Aueprasert and W. Wongthatsanekorn, "Application of lean technique for outpatient service time improvement in public hospital of Thailand," Journal of Advances in Technology and Engineering Research, vol. 2, no. 6, pp. 34-46, 2016. doi: https://doi.org/10.20474/ jater-2.6.2

[8] R. S. Rekha, P. Periyasamy, and S. Nallusamy, "Lean tools implementation for lead time reduction in CNC shop floor of an automotive component manufacturing industry," Indian Journal of Science and Technology, vol. 9, no. 45, pp. 01-06, 2016.

[9] P. Ribeiro, J. Sá, L. Ferreira, F. Silva, M. Pereira, and G. Santos, “The impact of the application of lean tools for improvement of process in a plastic company: A case study," Procedia Manufacturing, vol. 38, pp. 765-775, 2019. doi: https://doi.org/10.1016/j.promfg.2020.01.104

[10] R. Romero-Silva and S. Shaaban, "Influence of unbalanced operation time means and uneven buffer allocation on unreliable merging assembly line efficiency," International Journal of Production Research, vol. 57, no. 6, pp. 1645-1666, 2019. doi: https://doi.org/10.1080/ 00207543.2018 .1495344

[11] P. Ghafoorpoor Yazdi, A. Azizi, and M. Hashemipour, “An empirical investigation of the relationship between Overall Equipment Efficiency (OEE) and manufacturing sustainability in industry 4.0 with time study approach," Sustainability, vol. 10, no. 9, p. 3031, 2018. doi: https://doi.org/10.3390/su10093031

[12] V. Ramakrishnan, J. Jayaprakash, C. Elanchezhian, and B. V. Ramnath, "Implementation of lean manufacturing in Indian SMEs-A case study," Materials Today: Proceedings, vol. 16, pp. 1244-1250, 2019. 